\title{
Teaching Business English through Translation
}

\author{
Vanessa Leonardi \\ University of Ferrara
}

\begin{abstract}
The present paper focuses on the role of translation in Business English teaching from a pedagogical perspective including both translation from L1 into L2 and vice versa. A basic premise of this article is that translation cannot be avoided in language acquisition and it should not be viewed as a negative interference but as a natural and useful tool in language learning. Translation is still regarded as some kind of mechanical linguistic transfer of meaning from one language to another and it is not included in those language skills normally covered by language courses. This paper argues that translation could prove to be a very useful tool to learn grammar, syntax, lexis and culture-related issues in both the source language (SL) and the target language (TL). Teaching a foreign language means teaching how that language is used in a variety of contexts. This is especially true of ESP which should not be thought of as a different kind of language but rather as a different approach to language learning. The present paper aims to provide the ESP teacher with an overview of translation as a perfect tool to teach Business English. Translation is a good pedagogical tool to use in Business English teaching because there are not always exact equivalents between English and other languages. While translating, students are encouraged to notice differences in structures and vocabulary and they have to develop methods and strategies to deal
\end{abstract}


with them. Translation is communication across cultures and as such it plays a significant role in Business environments.

Keywords: translation, language teaching, business English, ESP, globalisation, English as a Lingua Franca (ELF)

\section{Introduction}

Globalisation has had a dramatic impact on international communication practice as more and more people from different linguistic and cultural backgrounds come daily into contact. This situation requires the adoption of a common language, or lingua franca, which is English. Thanks to the historical and economic developments, among other reasons, of two of the most important English-speaking countries, namely Great Britain and the United States, English has acquired a supremacy status and nowadays it is undoubtedly and officially recognised as the World's Lingua Franca (Crystal 2003; Graddol 1997, 2006). The term lingua franca, according to Richards et al (1996: 214) 'originated in the Mediterranean region in the Middle Ages among crusaders and traders of different language backgrounds' and it is aimed at 'serving as a regular means of communication between different linguistic groups in a multilingual speech community', (Holmes 1997: 86). Many theorists and scholars agree upon the fact that the development of a lingua franca to facilitate communication exchanges between speakers of different languages has often been determined by the necessity to carry out trading and commercial activities in different parts of the world. Nowadays, the term English as a Lingua Franca (ELF) is used to refer to the English variety spoken by people whose mother tongue is not English (Firth 1996; Seidlhofer 2001).

The use or adoption of English in international settings, however, may pose both linguistic and cultural problems especially for non- 
native speakers. Furthermore, in the specific context of Business communication the correct use of English plays a significant role in terms of successful communication. All too often the incorrect use of English, both in terms of accents or pronunciation as well as grammar and functions, could create communication problems and even misunderstanding.

When teaching Business English, stress should not only be laid upon purely grammatical points, but should also focus on language functions and cultural issues in order to frame business communication as a kind of mediation between cultures. Students may be proficient in English but still fail to use it in appropriate situations. The role of translation is thus fundamental in teaching and showing students mediation strategies and both linguistic and cultural differences through employing a contrastive approach to language. Through translation, students can learn more about problemsolving strategies, improve their analytical skills and strengthen their grammatical and lexical competence and performance.

\section{Differences between General EFL and English for Specific Purposes (ESP)}

There are significant differences between general EFL and ESP as also many teachers of English would agree, although there are also similarities. The main focus in this section, however, is to discuss differences. First of all, it should be stressed that the purposes for learning English differ. In ESP courses, there is a need to learn English in order to perform specific job-related functions. There is more emphasis, therefore, on language in context or language functions rather than grammar and language structures in general. English is taught and integrated in the learners' subject area of interest. ESP should be thought of not as a different kind of language but a different approach to language teaching and this is 
why teaching instructions generally differ between ESP and general EFL. In general EFL courses, all the traditional language skills are covered, namely, Reading, Writing, Speaking and Listening whereas in ESP more emphasis can be given to only one or two of them according to students' needs. ESP teachers need to perform different tasks not only as language experts but also as content specialists.

Further to these considerations, this paper argues that the use of translation in ESP classes can be a very useful and comprehensive approach to language learning in that it can include all four language skills traditionally employed to test learners' competence and performance. At the same time, it can be used to practise only one or two language skills but not necessarily all of them at once.

\section{Translation as the 'Fifth' Language Skill}

Translation has been unpopular for years in foreign language classes due to the negative connotations resulting from the application of the so-called 'Grammar-Translation Method'. This approach to language was used in the past to teach Greek and Latin and eventually generalised to modern language teaching a few years later. The method was heavily criticised for the following reasons which, still to this day contributes to making translation appear an obsolete practice in foreign language courses. First, Instructions were given in the students' L1 so that there was little use of the target language. Second, vocabulary was taught through isolated word lists and so it was difficult for students to see that words may be used in different ways according to context because no context was actually provided. And third, Little attention was given to pronunciation.

This paper argues that translation, both from L1 into L2 and vice versa, is a very complex activity which cannot be reduced to a merely linguistic activity in which structures from one language are 
transferred to structures in another language. Translation needs to be contextualised, and as such it requires attention to both linguistic and extra-linguistic factors, such as culture for example. It is surprising to see how the Common European Framework of Reference for Languages does not include translation in its testing modalities to determine proficiency levels.

Recent literature in applied linguistics, however, has shown significant signs of revival of translation in language teaching (Malmkjaer 1998: 1). Translation is more and more frequently evaluated as a positive form of interference aimed at enriching rather than harming learners' competence and performance skills. The use of translation in language classes might, of course, have some limitations but also benefits should be explored and taken into consideration. Translation should not be seen, and consequently treated, as a completely different language skill as compared to Reading, Writing, Speaking and Listening because it is an activity which includes them and is, to a certain degree, dependent on them. Translation involves the following series of language skills.

\subsubsection{Reading}

Before starting translating a text, the source text (ST) should be read carefully and analysed in detail. Thus, through close reading and careful text analysis of the ST students can gain important insights into the comprehension of the text in order to avoid misinterpretations and/or misunderstandings. Before attempting a translation, the text should be read very carefully in order to determine the content in terms of what, how and why it is said. The text can be approached in two different stages, namely, pre-reading and critical reading stages. In the first case, students will get acquainted with the so-called 'skimming' and 'scanning' techniques which will allow them to further analyse and evaluate: the role of the title, the name of the author, the type of magazine in which the 
article is published, the subject matter, the importance of paragraph divisions as discussion markers, the beginning and ending of each paragraph, the importance of drawing a short outline of main points covered, the importance of relating the issue to a larger framework.

The pre-reading stage only takes a few minutes and it provides students with a good initial preparation to read the whole article in a faster and clearer way. Skimming and scanning techniques allow students to get a general understanding of the article whereas critical reading will require them to read through the whole article slowly and carefully, paying attention to every single word and sentence. Critical reading is aimed at developing critical and analytical understanding of the text through questions and replies.

\subsubsection{Writing}

Translation is an activity which requires good writing skills in each of the three main stages of a translation, namely, decoding the ST, transferring linguistic and cultural elements and meanings into the TL and encoding the text into the new language and context. A good translation should flow naturally, reproduce both the style and the context of the original text and respect the TL writing conventions. Translation, therefore, can help students improve their writing skills and, if the task is approached from a contrastive perspective, students have the opportunity to see and evaluate similarities and differences between different writing styles in different languages. They will end up with parallel texts where a contrastive analysis can be carried out.

If translation is carried out from the students' mother tongue to a foreign or second language, then translation can somehow be equated with any composition writing task commonly taught in any language course. If students are asked to write a commentary about all the difficulties encountered when translating the "passage" and the strategies used in order to deal with "them" then translation becomes a sort of composition. 
Writing skills can be enhanced by having students summarise the text in their own words. It could be useful to ask them to restate the main argument and the conclusion of the article in a single sentence. More useful, in terms of translation commentary, would be to let students explain, in their own words, how the author reached his or her conclusion, why they found it convincing or not and what kind of linguistic or cultural problems the text posed.

\subsubsection{Listening and Speaking}

Translation is a communicative activity practiced within a meaningful context (Nord 1997). Translation involves interaction between the teacher and the students to discuss rights and wrongs as well as problems related to the translation task. If this communication exchange takes place in the L2 before and after the translation this can help students enhance their oral skills (both listening and speaking). There are many similarities between the way students usually practise oral skills in foreign language classes and translation classes. In both cases students are asked to carry out a conversation on a selected topic using their L2. The fact of carrying out a conversation on translation problems will help students strengthen their level of understanding of the text, relate the text to similar topics covered in their L1, and improve their speaking strategies in order to talk to both the lecturer as well as other students, improve their listening skills through listening to both lecturers and students. Translation can be used to teach and eventually test reading, writing, listening and oral skills and if applied to an ESP context, then it can even serve the role of enhancing specific needs. These needs include grammatical, lexical and cultural knowledge.

\subsection{Translation as Grammatical Explanation}

ESP students tend to have a good level of grammar as a result of 
their general English learning. It is worth noting, however, that in particular specialised fields grammar may be characterised by a special set of rules. Broadly speaking, Business English is characterized by its simplicity, precision, objectivity, efficiency and courtesy. This implies a different way to use grammar in business texts, especially in authentic texts whose use to exploit grammar may, at times, pose several problems. Authentic texts are characterised by numerous examples of grammatical structures and therefore the ESP teacher needs to identify commonly used or re-occurring structures in business texts. If texts are taken from newspapers, for instance, there might be some interesting and special rules of grammar. For example, the headlines are meant to be ambiguous in terms of comprehension in that they do not always contain a complete sentence.

Another interesting point is that business texts taken from newspapers tend to employ the simple present form instead of more complex structures. The present continuous is also used, at times, but the auxiliary tends to be omitted. A very common structure is the infinitive to refer to the future and passives are found with no auxiliary. Articles and the verb 'to be' also tend to be left out.

One of the most useful tips, in terms of grammar, would be to teach students a basic distinction between simple and complex sentence structures and to highlight differences in translation from one language to another. Italian, for instance, tends to be characterised by very long periods and complex sentence structures as compared to English. Particular attention should be given to the translation of noun-phrases which, especially in specialised texts, often tend to be employed in order to present a concept in a more compact and succinct way. It is interesting to note how both the number and the length of noun phrases in a text can affect the readability of sentences and therefore the overall comprehension. This is especially true in those cases where there is some sort of ambiguity due to the use in English of nominal phrases as in the following example taken from Walker (2005): 
(1) decreased water tolerance phenomenon

This sentence can be interpreted in three possible ways with three possible translations:

(2) the phenomenon of tolerance of decreased water (il fenomeno di tollerare la diminuzione di acqua)

(3) decreased tolerance phenomenon to water (il fenomeno diminuito di tolleranza all'acqua)

(4) the phenomenon of water's decreased tolerance (il fenomeno di una minor tolleranza da parte dell'acqua).

All these interpretations could possibly be correct and so there is a need to contextualise the text and see whether we can work out the correct meaning from the context itself. At times, this happens because the original text has been written without respecting writing conventions. The use of the possessive case or particular punctuation could serve to disambiguate the meaning as in the following examples:

(5) decreased water-tolerance phenomenon

(6) decreased phenomenon of water tolerance

Translation can play a very important role in this respect and, as Petrocchi (2006: 3) correctly acknowledges, 'By starting from grammar, students can reach higher level of translation and, vice-versa, by translating they acquire more competence in the knowledge of grammatical structures'. This mutual or reciprocal relationship will, in turn, help students improve their business communication skills (both oral and writing skills). 


\subsection{Translation as Vocabulary Builder}

ESP teachers should be aware of the importance of incorporating vocabulary teaching into their classes. Vocabulary seems to be one of the most commonly misunderstood aspects of language teaching. Most of the times, vocabulary is approached in a very unsystematic way which creates confusion for learners. When teaching vocabulary, teachers should not focus on every single word because there is no need and no time to do it. It is fundamental to help learners build their initial vocabulary by teaching them what is meant by 'learning words' and showing them how to learn the words most effectively.

Specialised vocabulary may not seem to be the primary goal of ESP language, but learners in these fields need to acquire their specialised terminology in order to better perform in their professions. Vocabulary is a key element in any second language class because whereas grammar is important for meaning, without vocabulary no message is conveyed. There seems to be a tendency, especially in ESP courses, to provide students with word-lists and ready-made glossaries to help them acquire specialised vocabulary. Vocabulary, however, does not mean simply 'words' because words are seldom found in isolation. For any given word, indeed, there is always a wide range of other words which can occur or collate with it. These word combinations or relationships, often called collocations, are very important for learners and most of the time, serious errors occur as a result of a lack of translational equivalence between the first language (L1) and the second language (L2).

In ESP, students have to learn high-priority lexis first, although in order to avoid lack of comprehension, low-frequency lexical items cannot be ignored either. Students should be taught to not translate word-for-word because ESP lexical items are contextbound and can have a wide range of possible meanings according to the context. The problem is that in some languages courses students are taught to learn language from word-lists in isolation from context, 
it being claimed that this method allows students to learn faster as compared to learning in context. Referring to the pragmatic concept of 'meaning in context', ESP vocabulary should take place according to the following guidelines: First, the text chosen for translation should be authentic, and second, the text should be contextualised because learning vocabulary involves a much more complex task than simply memorising words and phrases which have different meanings and can be used differently according to context or to collocations. In a contrastive bilingual situation, students can, thanks to translation, improve their ability to find an equivalent in L1 to match a lexical phrase in L2. Translation can teach students to learn vocabulary in two stages: students are taught to make a connection between the meaning and the form of the word, and then they must learn when to use or not use the word, its word relationships, its nuances, and so on.

According to some of the most influential ESP theorists (Robinson 1991; Hutchinson \& Waters 1987; Dudley-Evans \& St. John 1998), the teaching of vocabulary in the ESP class can be divided into three compartments: (1) technical vocabulary, where words are monosemic and are used exclusively in the domain in which they were created; (2) sub-technical vocabulary, where words are taken from the general language but have acquired one or several new meanings within the specialised field of application. Words, in this case, are polysemic retaining their original meaning and, at the same time, adding the meanings coming from the specialised area; and (3) general vocabulary of frequent use in a specific area, where words come from the general language and retain their meaning in the specialised field. Words are not technical terms, but they are nevertheless needed in order to gain a full understanding of the text.

One of the best vocabulary strategies to teach is to 'guess unknown words from context'. This task consists in teaching students to determine first a word's part of speech, and then they should look for clues around the word to help with the meaning. The next step is to 
ask them to replace that word with a synonym and see whether it makes sense. In the ESP context this could be done more easily as compared to general EFL classes because the command of English is higher and ESP students have already acquired a good knowledge of general English. Business English written language is often characterised by the extensive use of collocations and idiomatic expressions, but also by standard phrases which are typically used in business situations.

\subsection{Translation as Cultural Mediation}

Translation is a mediating activity which always takes culturebound terms and concepts into account in order to be successful in its transposition of a text from one language into another. Business and financial texts are characterised by a large number of culturebound terms and references which should be known by students in order to boost their comprehension of texts.

In an increasingly globalized world, paradoxically, the use of a single language, albeit English, does not automatically imply a common culture shared by everybody in the world. Although English has become the world's lingua franca, especially in the business world, the way it is spoken and perceived may cause serious cases of miscommunication and misunderstanding when it is employed either outside the national boundaries or by non-native speakers. Grammar and vocabulary may be correctly employed, but cultural references and the appropriate use of English in specific situations may be a totally different matter. This is why cultural explanations should be provided. Translation can help students improve their understanding of culturally-oriented terms by employing a contrastive approach in which analytical skills are required to find an equivalent term in the target language.

One of the most difficult tasks teachers of Business English face is finding the best way to teach students to appreciate cultural 
differences and to evaluate their effects on business communication, especially in international settings. From time to time, many language courses tend to teach some cultural features but there is not enough emphasis laid upon the awareness of cultural differences or how to behave in certain situations. Translation can raise this kind of awareness and teach students strategies and techniques to adapt their use of English to learn about, understand and even appreciate other cultures.

Everybody seems to agree upon the fact that cultural differences do exist. In the business world, issues such as etiquette and corporate culture seem to suggest that besides acquiring linguistic skills people also need to acquire cultural awareness. Culture tends to be reflected in diverse aspects of the business world ranging from office furniture to business meetings. Understanding cultural differences and relating them to one's culture can provide a starting point to anticipating and understanding some of the cultural differences that exist in everyday situations and preparing students to change their individual business behaviour and style. Translation, therefore, becomes a form of cultural mediation which is needed in order to carry out communication across cultures.

\section{Concluding Remarks}

The aim of this paper is to show how the use of translation in language courses, and in business English teaching in particular, can prove to be a comprehensive tool in that it includes all four traditional language skills, that is, reading, writing, speaking and listening. Moreover, translation allows students to better focus on one or more of those skills in a contrastive manner and to mediate the message from one language into another. Translation inevitably involves cultural mediation which, especially in the business world, plays an important role in terms of successful communication. Languages cannot be taught and learnt in isolation, but need to be 
contextualised and based on real-event issues just like a translation. Thanks to translation students can develop and further improve both their analytical as well as their mediation skills and are taught strategies to overcome language barriers and find equivalent and suitable terms and concepts in other languages.

\section{References}

Crystal, D. 2003. English as a Global Language (2nd edition). Cambridge: Cambridge University Press.

Dudley-Evans, T. \& M. John. 1998. Developments in ESP. Cambridge: Cambridge University Press.

Firth, A. 1996. The Discursive Accomplishment of Normality: on

'Lingua Franca' English and Conversation Analysis. Journal of Pragmatics 26, 237-59.

Graddol, D. 1997. The Future of English. London: The British Council. 2006. English Next. London: The British Council.

Holmes, J. 1997. An Introduction to Sociolinguistics. London: Longman.

Hutchinson, T. \& A. Waters. 1987. English for Specific Purposes: A Learning-centred Approach. Cambridge \& New York: Cambridge University Press.

Malmkjaer, K. 1998. Translation and Language Teaching, Language

Teaching and Translation. Manchester: St Jerome Publishing.

Nord, C. 1997. Translating as a Purposeful Activity: Functionalist Approaches Explained. Manchester: St Jerome Publishing.

Petrocchi, V. 2006. Translation as an Aid in Teaching English as a Second Language. Online Translation Journal 10(4). Retrieved 10 December 2008. Available at URL <www.accurapid.com> Richards, J. et al. 1996. The Longman Dictionary of Language Teaching \& Applied Linguistics. Harlow: Longman. 
Robinson, P. 1991. ESP Today: A Practitioner's Guide. Hertfordshire: Prentice Hall.

Seidlhofer, B. 2001. Closing the Conceptual Gap: The Case for a Description of English as a Lingua Franca. International Journal of Applied Linguistics 15(1), 133-57.

Walker, M. 2005. Scrivere l'inglese medico, online guide. Retrieved 12 December 2008. Available at URL <www.pensiero.it> 